\title{
Exposure as Collected Planned Time Point Number
}

National Cancer Institute

\section{Source}

National Cancer Institute. Exposure as Collected Planned Time Point Number. NCI

Thesaurus. Code C117502.

The numerical identifier of a collected exposure point in time. 